\title{
VIEJAS HISTORIAS DE CASTILLA LA VIEJA (1969): INSERCIÓN DE LAS PAREMIAS EN EL TEXTO LITERARIO DE MIGUEL DELIBES
}

Palabras clave: Miguel Delibes, paremia, modos de inserción

\section{Introducción}

Este artículo $^{1}$ forma parte de un estudio realizado con motivo de la celebración de las Jornadas Internacionales sobre la fraseología en la obra de Miguel Delibes, los días 9, 10 y 11 de febrero de 2011 en la Universidad Complutense de Madrid. En dicho estudio abordamos dos aspectos paremiológicos claves para el análisis y la comprensión de la obra delibiana:

- Por un lado la presencia de paremias ${ }^{2}$ y el modo de inserción de las mismas en la obra Viejas historias de Castilla la Vieja (1969), que abordaremos en este artículo;

- Por otro lado, la búsqueda de correspondencias paremiológicas ${ }^{3}$ en la traducción titulada Vieilles histoires de Castille realizada por Rudy Chaulet en el año 2000 para las ediciones Verdier, siendo éste último objeto de una publicación que verá la luz próximamente.

Centrándonos ya en el tema que nos ocupa, esto es, el análisis de los modos de inserción de paremias en el texto literario empleado por Miguel Delibes en su obra, debemos señalar que para la elaboración del presente trabajo, hemos utilizado la edición de Viejas Historias de Castilla la Vieja de Alianza Editorial en su edición de bolsillo del año 2010 .

En esta obra, que consta de diecisiete capítulos ${ }^{4}$, Delibes narra con precisión, riqueza y naturalidad la vida cotidiana, reiterativa e intemporal del entorno geográfico de los pueblos de Castilla. Refleja unas costumbres y un lenguaje propio de una época, de un

1 Este trabajo se inscribe en el Proyecto de Investigación I+D El mínimo paremiológico. Opciones metodológicas y su aplicación a la didáctica de lenguas (2005-2008. HUM2005-03899/FILO, Ministerio de Educación y Ciencia) y en Ampliación del mínimo paremiológico (2008-2011. FFI2008-02681/FILO, Ministerio de Ciencia e Innovación de España).

2 «Paremia», es el archilexema del universo proverbial, es un enunciado breve, sentencioso, consabido, engastado en el discurso, de forma fija y con características lingüísticas fijas propias. (Sevilla Muñoz, 1993: 15).

3 En traducción, la correspondencia paremiológica consiste en localizar en la lengua terminal o lengua meta, la paremia que más se aproxima al sentido, al uso y a la forma de la paremia en la lengua de origen (Sevilla Muñoz, 2004: 224).

4 Los capítulos que conforman la obra se titulan: 1. El pueblo en la cara, 2. Aniano, el Cosario, 3. Las nueces, el autillo y el abejaruco, 4. La pimpollada del páramo, 5. Los hermanos Hernando, 6. El teso macho de Fuentetoba, 7. Las cangrejadas de San Vito, 8. La Sisinia, mártir de pureza, 9. Las murallas de Ávila, 10. Los nublados de Virgen a Virgen, 11. A la sombra de los enamorados, 12. El matacán del majuelo, 13. Un chusco para cada castellano, 14. Grajos y avutardas, 15. Las Piedras Negras, 16. La Meseta de los Muertos, 17. El Regreso. 
medio social y de una cultura determinada y dentro de ese lenguaje propio, las paremias (refranes ${ }^{5} \mathrm{y}$ frases proverbiales ${ }^{6}$ fundamentalmente) ocupan un lugar preponderante, pues como veremos más adelante, el autor recurre a estas manifestaciones de la sabiduría popular en diversas ocasiones.

La presencia de las paremias resulta destacada no sólo por la riqueza cultural que vehiculan sino por el modo en que Delibes las inserta en los discursos de sus personajes y cómo, en ocasiones, simplemente alude a ellas de manera indirecta.

Hemos realizado una clasificación general del modo en que las paremias se insertan en un texto. Según Barsanti Vigo (2008: 57) las paremias pueden aparecer incorporadas directamente o indirectamente en la conversación. En el primer caso, se introducen en el discurso sin aludir al hecho de que se trata de un enunciado sentencioso, y en el segundo, son introducidas mediante el empleo fórmulas 'como dice el refrán', 'como dice aquel', 'como se suele decir', etc.

Hemos distinguidos tres tipos fundamentales de enunciación, Enunciación Directa Total, Enunciación Directa Parcial y Enunciación Evocada o Referida. De ellas, tan sólo la Enunciación Directa Total y la Enunciación Evocada o Referida son empleadas por Delibes en esta obra.

\section{Enunciación Directa Total}

La Enunciación Directa Total (EDT) es aquella en la que la paremia aparece insertada en una de sus formas canónicas, es decir, en una de las formas comúnmente aceptada por una misma comunidad hablante, aparece introducida directamente en el texto y con su estructura completa, sin alteración alguna (truncamiento, desautomatización), sin ningún tipo de elemento introductorio, como un elemento más del discurso en el que se insertan.

Los refranes pueden funcionar como elementos independientes o dependientes del discurso y pueden mantener una relación de coordinación o subordinación respecto a los demás elementos oracionales (Barsanti Vigo, 2008). Veamos unos ejemplos de Enunciación Directa Total:

-¿Qué le habéis hecho a Carlitos, que se sube a Personal a pedir el traslado? Hoy es que estáis imposibles.

-Nada -explicó caritativamente Satur-, que éste le ha dicho que se iba a cegar en la señora Macusani.

-Pero no lo he hecho. Lo que pasa es que lleva una temporada que quiere trasladarse. La prueba es la matraca que nos ha dado con lo del catalán. Si no fuese por él, podíamos tener

5 El «Refrán» es una paremia de uso popular, de temática general y práctica, estructura generalmente bimembre que posee elementos mnemotécnicos. A veces posee sentido metafórico y cierta jocosidad. (Sevilla Muñoz y Cantera, 2002:19). Por ejemplo: Más vale maña que fuerza, Piedra movediza, moho no cobija.

6 La «Frase proverbial» es una paremia popular desprovista de elementos mnemotécnicos, unimembre, con ausencia de rima y con frecuencia, de una elaboración formal que consta a veces de una fórmula que expresan orden o mandato. (Sevilla Muñoz, 1993: 17). Por ejemplo: No hay que empezar la casa por el tejado, No se hay que mentar la soga en casa del ahorcado. 
ya los cuestionarios entregados. ¿Que se va? ¿Que se vaya! A enemigo que huye, puente de plata.

-Ay, benditos, cómo sois... -a Guadaesferasrutilantes en la penumbra del pasillo le brillaba el tambor de su vientre-. Con lo a gusto que viviríamos todos en paz ... (García Hortelano, [1972] 1999: 279)

En la obra Viejas historias de Castilla la Vieja Delibes emplea este tipo de enunciación en el ejemplo siguiente, en el que podemos observar que la paremia aparece insertada en el discurso directo como una oración o rezo en boca de la tía Marcelina:

\section{Ejemplo 1:}

De vez en cuando sonaba algún trueno más potente y al Coqui, el perro, se le erizaban los pelos del espinazo y la tía Marcelina interrumpía el trisagio, se volvía a la estampa de Santa Bárbara e imploraba: «Santa Bárbara [4 diciembre] bendita, que en el cielo estás escrita, con jabón y agua bendita», y, acto seguido, reanudaba el trisagio: «Santo Dios, Santo Fuerte, Santo Inmortal», y nosotros respondíamos al unísono: «Líbranos Señor de todo mal».

(10. Los nublados de Virgen a Virgen, p. 46)

Dentro de la Enunciación Directa Total, podemos observar que en numerosas ocasiones la paremia en su forma canónica o estándar aparece precedida de ciertos elementos introductorios que indicarían o revelarían su presencia en el texto, en estos casos la denominamos Enunciación Directa Total Anticipada.

\subsection{Enunciación Directa Total Anticipada}

La Enunciación Directa Total Anticipada (EDTA) hace referencia a la introducción de la paremia en el discurso en su forma más conocida o estándar mediante una fórmula introductoria del tipo 'como dice el refrán', ‘como dice mi abuelo', ‘¿recuerdas aquello de?', que capte la atención del lector sobre el enunciado sentencioso que se va a encontrar en el texto (Sardelli, 2010a: 333-334):

Las vecinas echaban todas su cuarto a espadas por recetarla yerbas, pero como la que mayor fe nos daba era la señora Engracia, a ella hubimos de recurrir y a sus consejos, por ver de sanarla; complicada fue, bien lo sabe Dios, la curación que la mandó, pero como se le hizo poniendo todos los cinco sentidos bien debió de probarla, porque aunque despacio, se la veía que le volvía la salud. Como ya dice el refrán, yerba mala nunca muere, y sin que yo quiera decir con esto que Rosario fuera mala (si bien tampoco pondría una mano en el fuego por sostener que fuera buena), lo cierto es que después de tomados los cocimientos que la señora Engracia dijera, sólo hubo que esperar a que pasase el tiempo para que recobrase la salud, y con ella su prestancia y lozanía. (Cela, 1942 [1995]: 47)

Delibes emplea este tipo de enunciación en dos ocasiones, la primera para referirse a la paremia El que quiera peces que se moje el culo, y la segunda para en el país de los 
ciegos el tuerto es el rey; en ambas ocasiones aparecen enunciadas en el discurso narrativo del protagonista de la obra, presumiblemente Miguel Delibes:

\section{Ejemplo 2:}

Por entonces las cosas no estaban reglamentadas con rigor y uno podía pescar cangrejos con reteles, como es de ley, o con araña, esparavel o sencillamente a mano, mojándose el culo, como dice el refrán que debe hacer el que quiera comer peces.

(7. Las cangrejadas de San Vito, p. 34)

\section{Ejemplo 3 :}

Padre decía a menudo: «Castilla no da un chusco para cada castellano», pero en casa comíamos más de un chusco y yo, la verdad por delante, jamás me pregunté, hasta que no me vi allá, quién quedaría sin chusco en mi pueblo. Y no es que Padre fuese rico, pero ya se sabe que el tuerto es el rey en el país de los ciegos y Padre tenía voto de compromisario por aquello de la contribución. Y, a propósito de tuertos, debo aclarar que las argayas de los trigos de mi pueblo son tan fuertes y aguzadas que a partir de mayo se prohíbe a las criaturas salir al campo por temor a que se cieguen.

(13. Un chusco para cada castellano, p. 58)

\section{Enunciación Directa Parcial}

Se trata de Enunciación Directa Parcial (EDP) cuando se introduce tan sólo un fragmento de la paremia, puede tratarse de la primera parte de la paremia, de una paremia bimembre en origen que se ha conservado como paremia unimembre como En abril aguas mil o Mañana será otro día, que son tan sólo la primera parte de dos paremias más largas: En abril aguas mil, y si no las vieres, año de nieves y Mañana será otro día y verá el tuerto los espárragos.

Este procedimiento suele denominarse truncamiento ${ }^{7}$, que describe comúnmente la omisión del segundo miembro del refrán, si bien, en ciertos casos la omisión, o pérdida de material fónico, «puede afectar circunstancialmente a los dos miembros de la unidad paremiológica». (Fasla, 1999: 162).

Hugo Bizzarri (2004) denomina este tipo de unidades fragmentadas refranes diluidos, fenómeno que se produce cuando el autor juega con la doctrina y los diversos componentes de la paremia sin reproducirla en su forma canónica y construye sus oraciones a partir de una paremia conocida, de manera que «conserva el fondo doctrinal de la paremia, sus diferentes elementos constitutivos, pero no su formulación» (Bizzarri 2004:

\footnotetext{
No debe confundirse «truncamiento» con la desautomatización o el «détournement». Para el investigador Alberto Zuluaga (1992: 128) los procedimientos de desautomatización «consisten en aplicar determinadas operaciones dentro del sistema gramatical actual (permutaciones, inserciones, sustituciones, etc.). Es frecuente encontrar el uso de este procedimiento en el lenguaje juvenil: ojos que no ven, gabardina que te roban es una desautomatización de ojos que no ven, corazón que no siente».

Con respecto al procedimiento de «détournement» afirma Peter Barta (2005: 140): «Un proverbe détourné (on dit aussi derivé ou tordu) est une parodie du proverbe, une unité phraséologique derrière laquelle on peut reconnaitre un proverbe concret».
} 
149). Dado que este procedimiento se puede producir tanto en refranes como en otro tipo de unidades paremiológicas (véase, frases proverbiales o locuciones proverbiales), hemos optado por emplear la categoría señala por M. ${ }^{a}$ Antonella Sardelli (2010b: 81) de paremias diluidas, que la autora define de la siguiente manera:

Las paremias diluidas son aquellas que resultan de la capacidad del autor de jugar con un enunciado conocido para adaptarlo al contexto en el que se inserta. De este modo, algunos de los componentes de las paremias se podrán identificar con cierta facilidad, lo que permitirá reconstruir la forma canónica de la paremia en cuestión.

La denominamos Enunciación Directa Parcial porque la parte de la paremia que es introducida, lo es de manera directa, en el discurso mismo, sin elementos introductorios. Veamos dos casos. En el primero observamos cómo aparece tan sólo la primera parte de la paremia $A$ caballo regalado, no le mires el diente, y en el segundo caso, La suerte de la fea, la guapa la desea:

Era un diálogo apasionante y encantador.

-¿Cómo está Toni?- preguntó Sonia

-Bien -dije-. Tronó con Juan Luis, pero anda con un antropólogo muy guapo.

- ¿Toni? -Se asombró Clara con mala leche

-Sí-dije- Toni, puros guapos.

-La suerte de la fea ... -dijo Clara.

-Tú también tienes suerte - dijo Julio-, y eso que tan fea no eres.

-iJa! -Exclamó Clara-. ¿Dónde esté mi suerte?

Julio se quedó cortado. Todos nos quedamos cortados. Pasó un ángel. Un ángel nada alegre.

Los niños se levantaron. (Villegas, 1995: 230)

Delibes emplea esta técnica en una ocasión (ejemplo 4), al aprovechar sólo una parte de una paremia de origen italiano en su narración.

\section{Ejemplo 4:}

Mi tío Remigio era flaco y anguloso y nada había redondo en su cuerpo fuera de la coronilla y, cuando yo le pregunté si se sabía cura desde chico, tardó un rato en contestar y al fin me dijo: «Yo oí la voz del Señor cazando perdices con reclamo, para que lo sepas». Yo me quedé parado, pero, al día siguiente, el tío Remigio me dijo: «Vente conmigo a dar un paseo». Y pian pianito nos llegamos a las Piedras Negras. Él se sentó en una de ellas y yo me quedé de pie, mirándole a la cara fijamente, que era la manera de hacerle hablar.

(15. Las Piedras Negras, p. 66)

En este caso, pian pianito es un componente que nos permite identificar fácilmente la paremia a la que hace referencia, que nos es otra que una parte del refrán italiano Piano, piano, si va lontano o Chi va piano, va sano e va lontano, que ha dado lugar al refrán en español Piano, piano, se va lontano. 
En el siguiente ejemplo (ejemplo 5), el fragmento de la paremia alude a una paremia conocida por el eventual lector de la obra de Delibes, y que por tanto, debe conocer y comprender el significado de la locución ir en el coche de San Fernando que no es más que la primera parte de la paremia diluida Ir en el coche de San Fernando, un ratito a pie y el otro andando.

\section{Ejemplo 5:}

De allá yo regresé a Madrid en un avión de la $\mathrm{SAS}^{8}$, de Madrid a la capital en el Taf ${ }^{9}$, y ya en la capital me advirtieron que desde hacía veinte años había coche de línea a Molacegos y, por lo tanto, no tenía necesidad de llegarme, como antaño, a Pozal de la Culebra. Y parece que no, pero de este modo se ahorra uno dos kilómetros en el coche de San Fernando.

(17. El regreso, p. 73)

\subsection{Enunciación Directa Parcial Anticipada:}

Se produce Enunciación Directa Parcial Anticipada (EDPA) cuando se introduce tan sólo un fragmento de la paremia. Puede tratarse de la primera parte de la paremia o de un fragmento de la misma pero introducida por una partícula del tipo 'como dicen por ahí', 'como dice el refrán', etc. Veamos un ejemplo:

- ¿Qué se dice de la bolsa hoy? Aún no me traen de mi agencia de noticias los cilindros.

-Parece que siguen subiendo las acciones de la Compañia Transatlántica de Aeroplanos. ¿Sabes que no sería malo deshacerse de las acciones de la Submarina?

${ }_{-}^{\text {¡No! }}$ Yo creo que se trata de una crisis pasajera ... ya verás ...

-No es difícil, sólo que «mujer prevenida» ..., como dice el refrán. Pero ya es tarde. Voy a ver si está listo mi aerocab. ¡Adiós! ¿Irás a la noche al Cinema-Club?

-Sí, allá nos veremos. Dicen que hay ya películas coloridas del desastre del gran puente de la Mancha.

$-Y$ de la última comunicación. Parece que eso es muy curioso ...

-Hasta luego, pues.

-Hasta luego. (Nervo, [1971] 1993: 152)

Delibes no emplea esta técnica a lo largo de la obra, pero no nos cabe duda de que, dado su profundo conocimiento del lenguaje popular, existe la posibilidad de que la hubiera utilizado en otra de sus obras, pues se trata de una técnica muy habitual, especialmente cuando se trata de escenas dialogadas, que no abundan mucho en la obra que nos ocupa, y si los hay, son breves.

SAS: Siglas de la compañía aérea Scandinavian Airlines System.

9 La entrada en servicio de estos trenes se produjo en el año 1952, siendo construidos en Italia por FIAT, de donde deriva su nombre Tren Automotor Fiat, siguiendo el diseño de los trenes italianos en servicio en aquel momento. (Fuente: http://www.ibertren.es) 


\section{Enunciación Evocada o Referida}

La presencia indirecta o aludida de una paremia se produce cuando el autor hace referencia a una paremia que pertenece al acervo colectivo mediante una pista o guiño al lector, mediante meras alusiones a hechos proverbiales o al uso de uno de los términos clave de la paremia referida, como si se tratase de un eco. Como señala Sardelli (2010b: 83) la identificación de este tipo de enunciados, que la autora denomina paremias aludidas, es «totalmente subjetiva, pues depende de la competencia paremiológica de cada lector». La autora señala un ejemplo en el Cancionero de Sebastián de Horozco, para ilustrar su teoría de paremias aludidas en el que podemos observar cómo el autor se refiere, de manera indirecta a la paremia Allégate a los buenos, y serás uno de ellos:

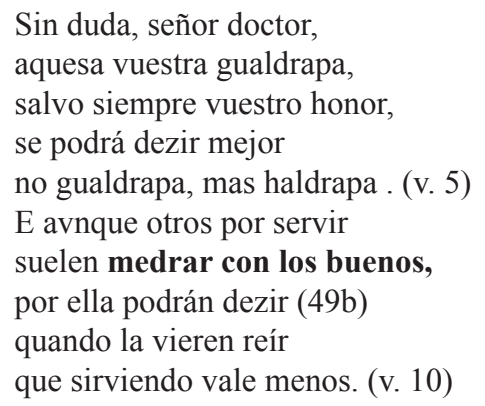

(Sebastián de Horozco)

Delibes utiliza este tipo de inserción de paremias en el texto en dos ocasiones. En el fragmento siguiente (ejemplo 6), el autor describe de manera indirecta la paremia sobradamente conocida Si la montaña no va a Mahoma, Mahoma va a la montaña y utiliza el saber colectivo del lector para, mediante la alusión al refrán, explicar cómo 'Padre' solía ir al desierto a reflexionar sobre asuntos de importancia, del mismo modo que Mahoma iba a la montaña a meditar.

\section{Ejemplo 6 :}

Mas antes de ser aquello la Pimpollada y antes de traer la luz de Navalejos, Padre solía subir a aquel desierto siempre que se veía forzado a adoptar alguna resolución importante. Don Justo del Espíritu Santo, el señor cura, que era compañero de seminario de mi tío Remigio, el de Arrabal de Alamillo, decía de Padre que hacía la del otro y, al preguntarle quién era el otro, él respondía invariablemente que Mahoma. $Y$ en el pueblo le decían Mahoma a Padre aunque nadie, fuera de mí y quizá don Benjamín que tenía un Hunter inglés para correr las liebres, sabía allí quién era Mahoma. Yo me sé que Padre subió varias veces al páramo por causa mía, aunque en verdad yo no fuera culpable de sus disgustos, pues el hecho de que no quisiera estudiar ni trabajar en el campo no significaba que yo fuera un holgazán.

(4. La Pimpollada del páramo, p. 22)

A continuación aventuramos una posible referencia indirecta a la paremia los tiempos cambian, lo esencial permanece. Lo que nos permite hacer esta reflexión es la idea 
que advierte que el tiempo sólo hace cambiar el aspecto externo de las cosas, pero que lo fundamental permanece. Tengamos en cuenta que esta reflexión se produce en el último capítulo de la obra, cuando el protagonista, Delibes mismo, regresa a su pueblo cuarenta y ocho años después de haber salido, y percibe que casi medio siglo después de su partida, a pesar de los cambios sociales y tecnológicos que había experimentado la España de entonces y que él había vivido, en su pueblo, en el campo nada había cambiado, los hombres seguían teniendo las mismas preocupaciones, la misma actitud ante la vida, y resulta casi proverbial la reflexión de Delibes sobre la inmutabilidad de determinados valores y actitudes.

\section{$>$ Ejemplo 7:}

Y así que doblamos el recodo vi ascender por la trocha sur del páramo de Lahoces un hombre con una huebra y todo tenía el mismo carácter bíblico de entonces y fui y le dije: «¿No será aquel que sube Hernando Hernando, el de la cantina?». Y él me dijo: «Su nieto es; el Norberto». Y cuando llegué al pueblo advertí que sólo los hombres habían mudado pero lo esencial permanecía, y si Ponciano era el hijo del Ponciano, y Tadeo el hijo del tío Tadeo, y el Antonio el nieto del Antonio ...

(17. El regreso, p. 74)

\section{Conclusión}

Los tres tipos de enunciación paremiológica anunciados Enunciación Directa Total, Enunciación Directa Parcial y Enunciación Evocada o Referida, nos han servido de marco para explicar cómo el conocimiento previo de los hablantes de una misma lengua de las unidades paremiológicas permite a Delibes establecer lazos afectivos con el lector.

Delibes recurre a las paremias en ocho ocasiones a lo largo de su novela, y emplea principalmente la Enunciación Directa Total y la Enunciación Evocada o Referida para introducir las paremias en el discurso de sus personajes.

Delibes refleja a la perfección la vida en su Castilla natal, refleja conversaciones, preocupaciones, alegrías, afanes o jolgorios, diálogos en los que introduce los refranes y las frases proverbiales como elementos culturales, fiel reflejo del lenguaje de Castilla.

El estudio del modo en que las paremias se insertan en el texto literario, permite comprender la naturaleza de las mismas y su función como argumento de autoridad dentro del relato.

Delibes demuestra en esta obra un gusto exquisito por la expresión correcta y el verbo apropiado, dando como resultado una excelente obra plagada de sensibilidad y contenido paremiológico. 


\section{BIBLIOGRAFÍA}

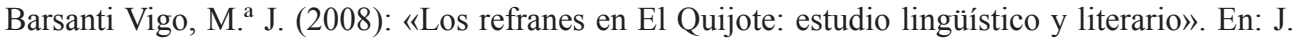
Sevilla, M. I. T. Zurdo y C. Crida (eds.): Los refranes y el Quijote. Atenas: Ta kalós keímena, 49-72.

Barta, P. (2005): «Au pays des proverbes, les détournements sont rois. Contribution à l'étude des proverbes détournés du français (I)», Paremia, 14, 61-70.

Barta, P. (2006): «Au pays des proverbes, les détournements sont rois. Contribution à l'étude des proverbes détournés du français (II)», Paremia, 15, 57-71.

Bizzarri, H. (2004): El refranero castellano en la Edad Media. Madrid: Ediciones del Laberinto.

Cela, C. J. (1942 [1995]): La familia de Pascual Duarte. Barcelona: Destino.

Delibes, M. (1969 [2010]): Viejas historias de Castilla la Vieja. Barcelona: Lumen.

Delibes, M. (2000): Vieilles histoires de Castille. Trad. Rudy Chaulet. Lagrasse: Éditions Verdier.

Fasla, D. (1999): «Conmutación léxica, relaciones semánticas y truncamiento paremiológico», Paremia, 8, 161-164.

García Hortelano, J. (1972 [1999]): El gran momento de Mary Tribune. Barcelona: Grupo Zeta.

García Yelo, M. (en prensa): «Las paremias en la traducción al francés de la obra de Miguel Delibes Viejas historias de Castilla la Vieja», Páginas de Guarda, 13.

Nervo, A. (1971 [1993]): Cuentos y crónicas de Amado Nervo. México: Universidad Nacional Autónoma de México.

Ruiz Zafón, C. (2008): El juego del Ángel. Barcelona: Planeta.

Sampedro, J. L. (1985 [1993]): La sonrisa etrusca, Barcelona: RBA Ediciones.

Sardelli, M. ${ }^{a}$ A. (2010a): «Los refranes en clase de Español Lengua Extranjera», Didáctica. Lengua y Literatura, 22, 325-350.

Sardelli, M. a A. (2010b): «Las paremias en el Cancionero de Sebastián de Horozco». En: José Labrador y Ralph Di Franco (eds.): Cancionero Sebastián de Horozco. Toledo: Consejería de Educación, Ciencia y Cultura, 71-122.

Sevilla Muñoz, J. (1993): «Paremias españolas: Clasificación, Definición y correspondencia francesa». Paremia, 2, 15-20.

Sevilla Muñoz, J. (2004): «O concepto correspondencia na traducción paremiolóxica», Cadernos de Fraseoloxía galega, 6, 221-229.

Sevilla Muñoz, J.; Cantera Ortiz de Urbina, J. (2002): Pocas palabras bastan; vida e interculturalidad del refrán. Salamanca: Centro Cultural Tradicional.

Villegas, P. (1995): La luz oblicua. México: Ediciones Era.

Wozniak, A. (2009): «Le proverbe détourné: étude théorique appliquée à un corpus bilingue franco-espagnol», Paremia, 18, 185-196.

Zuluaga Ospina, A. (1992): «Fraseología española». En: Günter Holtus [et al.] (eds.), Lexikon der Romanistischen Linguistik, 6, 1, Tübingen: Niemeyer, 125-131. 


\section{VIEJAS HISTORIAS DE CASTILLA LA VIEJA (1969): \\ PREGOVORI IN REKI V LITERARNEM BESEDILU MIGUELA DELIBESA}

Ključne besede: Miguel Delibes, pregovori in reki, načini vključevanja v besedilo

Avtorica članka predstavi osnovno klasifikacijo vključevanja paremij v besedila in analizira prisotnost treh osnovnih tipov izrekanja v literarnem besedilu Viejas historias de Castilla la Vieja (1969) španskega pisatelja Miguela Delibesa. To delo v sedemnajstih poglavjih opisuje vsakdanje, rutinsko življenje v kastiljskih vaseh v določenem kuturnozgodovinskem okolju, predvsem njihove običaje in jezik. Slednjega najbolj zaznamujejo prav raznolike paremije (prevsem pregovori in reki). Delibes z njihovo pomočjo prikaže specifiko ljudskega jezika, prepletenega s kolektivnimi referencami, tako da jih vključuje v diskurze protagonistov na dva osrednja načina: posrednega in neposrednega. 